\title{
Coronary intervention of an anomalous left main coronary artery arising from the right sinus of valsalva presented as acute coronary syndrome
}

\begin{abstract}
Anomalous origin of the left coronary artery (LCA) from the right sinus of Valsalva is a rare congenital Anomaly. We report a 38 year old male presented with acute coronary syndrome (ACS). Referred to the Catheterization laboratory for Percutaneous Coronary Intervention (PCI). The coronary angiogram showed the LCA originating from the right coronary sinus. A critical stenotic lesion was observed in the shaft of the Left main coronary artery. CT coronary angiography displayed a benign retro aortic course. The lesion was treated successfully with stenting.
\end{abstract}

Keywords: percutaneous coronary intervention, ct angiography, anomalous coronary artery, congenital coronary artery
Volume 5 Issue 6 - 2016

\author{
Saad Al Bugami, Mohammed W Althobaiti, \\ Jamilah Alrahemi, Abdullah J Alsaiedi, Wael Al \\ Kashkari \\ King Saud bin Abdulaziz University for Health Sciences, King \\ Abdulaziz Medical City, Saudi Arabia
}
Correspondence: Saad Al Bugami, King Saud bin Abdulaziz University for Health Sciences, King Abdulaziz Medical City, King Faisal Cardiac center, Jeddah 21423, Saudi Arabia, Email sbugami@gmail.com

Received: May 13, 2016 | Published: May 24, 2016

\section{Introduction}

Congenital anomalies of the coronary artery are rare it ranges between $0.2-1.3$ percent. ${ }^{1-5}$ Anomalous origin of the coronary arteries is considered an incidental finding without clinical significance; however, these abnormalities may be responsible for angina pectoris, acute coronary syndrome, heart failure and increased risk of sudden death. ${ }^{6}$ It is important to define the course of these anomalies and exclude malignant ones especially if intervention is contemplated. ${ }^{7}$ We describe a young patient with anomalous left coronary artery arising from the right coronary cusp who presented with acute coronary syndrome and the way he was treated.

\section{Case history}

38 year old male patient with 15 packs per year smoking history presented to a peripheral hospital with acute onset typical chest pain for 30 minutes. His ECG revealed ST- Elevation acute lateral wall myocardial infarction. He was thrombolyzed with t-PA with complete resolution of his ECG changes. Echocardiogram showed mild LV dysfunction with LVEF of $45 \%$ and lateral wall hypo kinesis. He was then transferred to our center where he was taken to the catheterization laboratory and diagnostic coronary angiogram was done following obtaining an informed consent. It was difficult to engage the left coronary artery with Judking left catheter. A right judkins was taken to visualize the right coronary system. This revealed that the right coronary artery to be free of disease (Figure 1) and the left coronary artery to originate from the right coronary sinus. The anomalous left main showed a mid-shaft hazy and eccentric lesion (Figure 2), Normal left anterior descending and normal left circumflex. The patient was discussed in a heart team meeting and it was decided to obtain coronary $\mathrm{CT}$ angiogram to define the course of the anomalous left coronary artery which was retro-aortic (Figure 3 ). The patient was offered bypass surgery of which he declined to accept. The patient informed decision was to opt for PCI. A straight forward intervention was carried out using Judging's 4 guiding catheter, which easily incubated the anomalous left main a BMW wire easily passed to the distal LAD and a direct $4.0 \times 22 \mathrm{~mm}$ resolute stent deployed (Figure 4). A second stent $4.0 \times 8 \mathrm{~mm}$ resolute stent deployed proximally to cover an area of plaque shift. A final IVUS was done which showed well stent apposition (Figure 5). The procedure was supplanted with $300 \mathrm{mg}$ of Plavix and 7000 unit of heparin. He was discharged next day.

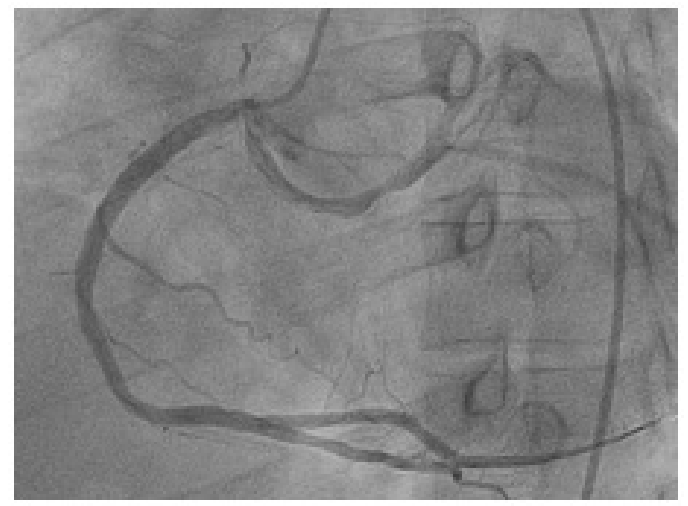

Figure I Coronary angiography showing right and left coronary arteries originating from the right cornary sinus of Valsalva.

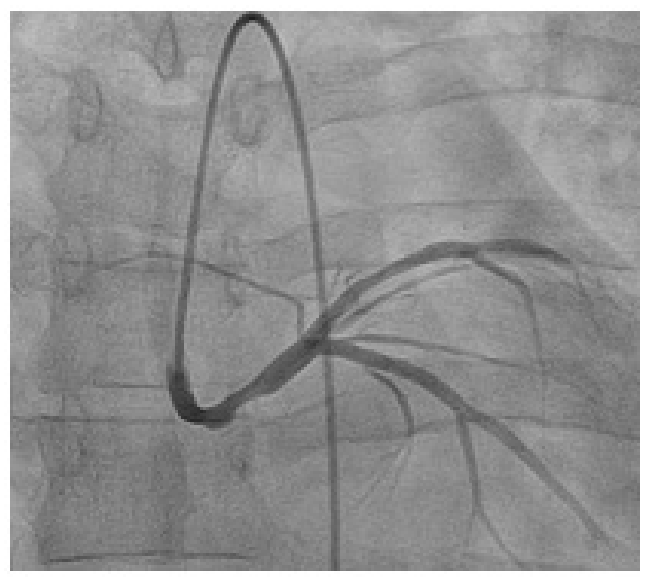

Figure 2 Selective engagement of the left coronary artery showing a hazyeccentric lesion in the left main shaft. 


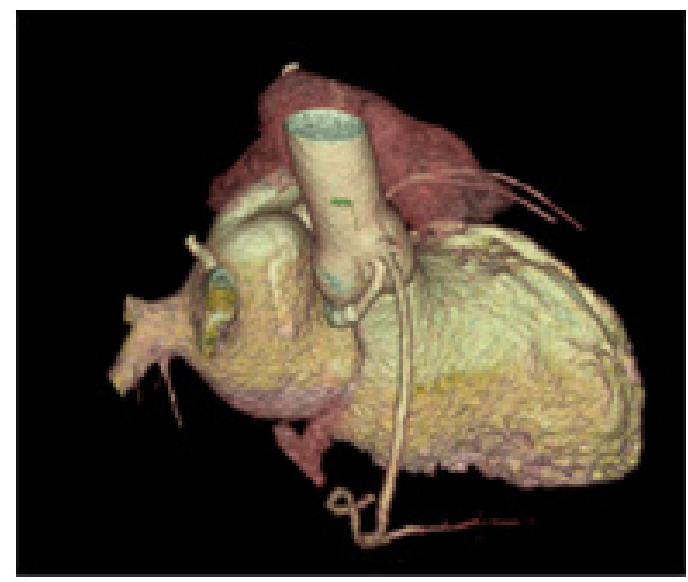

Figure 3 Volume rendered CT coronary demonstrating the retro aortic course course and the stent.

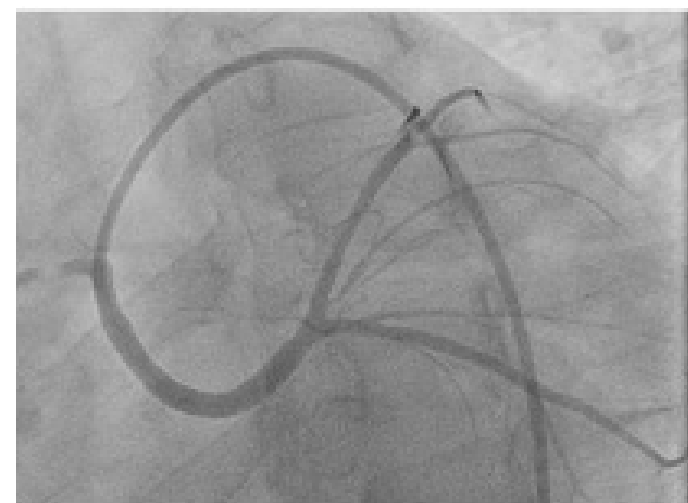

Figure 4 Post stenting of anomalous left main.

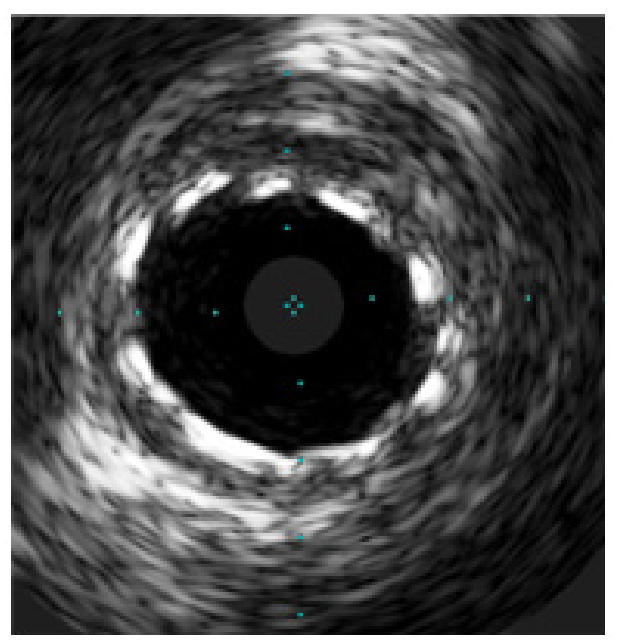

Figure 5 The final IVUS image of the stented segment with excellent apposition.

\section{Discussion}

Anomalous origin of the left coronary artery from the right sinus of Valsalva is an uncommon malformation, accounting for $0.15 \%$ of cases in the series of Angelina et $\mathrm{al}^{8}{ }^{8}$ this anomaly is further subdivided in to 4 subtypes depending on the course it follows. ${ }^{1}$ The left main coronary artery courses between the aorta and the pulmonary artery. ${ }^{2}$ The left main coronary artery tracks anteriorly over the right ventricular outflow tract. ${ }^{3}$. The left main coronary artery takes an intra myocardial course before resurfacing at the proximal portion of the inter ventricular groove. ${ }^{4}$ The left main coronary artery passes posteriorly around the aortic root. $^{8}$ Of these; the first anomalous configuration is classically considered the most dangerous placing patients at the highest risk of sudden cardiac death. ${ }^{9}$

It has been reported that anomalous coronary arteries are prone to atherosclerosis. ${ }^{10-12}$ The coronary blood flow would be disturbed in anomalous coronary arteries originating from the opposite side coronary sinus, which is located between the pulmonary trunk and the ascending aorta. ${ }^{13-16}$ Many patients with anomalous LCA arising from the right coronary sinus die before the age of 20 years and usually during or shortly after vigorous exertion. ${ }^{17-19}$ However, our patient did have a significant atherosclerotic changes in the anomalous Left main coronary artery. It appears that the cause of ACS in this patient might be related to coronary artery risk factors such as smoking rather than to the anomalous coronary artery itself which was found to have a more benign retro-aortic course.

\section{Conclusion}

We report a case with the retro aortic type of anomalous origin of the left coronary artery from the right sinus of Valsalva, this variant has been reported to have a relatively benign clinical course. The lesion in the left main coronary artery was thought to be due to atherosclerosis. It was decided to treat this patient percutaneously with direct stmplantation.PCI in anomalous coronary arteries is a feasible therapeutic strategy; however, accurate topographic identification of the origin and proximal course of the anomalous vessel is of paramount importance before proceeding in proceeding with these interventions..$^{20}$

\section{Acknowledgments}

None.

\section{Conflicts of interest}

The authors declare no conflicts of interest.

\section{Funding}

None.

\section{References}

1. Click RL, Holmes DR, Vlietstra RE, et al. Anomalous coronary arteries: location, degree of atherosclerosis and effect on survival-a report from the Coronary Artery Surgery Study. J Am Coll Cardiol. 1989;13(3):531-537.

2. Wilkins CE, Betancourt B, Mathur VS, et al. Coronary artery anomalies. A review of more than 10,000 patients from the Clayton Cardiovascular Laboratories. Tex Heart Inst J. 1988;15(3):166-173.

3. Kardos A, Babai L, Rudas L, et al. Epidemiology of congenital coronary artery anomalies:a coronary arteriography study on a central European population. Cathet Cardiovasc Diagn. 1997;42(3):270-275.

4. Akcay A, Tuncer C, Batyraliev T, et al. Isolated single coronary artery:a series of 10 cases. Circ J. 2008;72(8):1254-1258.

5. Dubey L. Percutaneous coronary intervention of an obstructive left anterior descending artery with anomalous origin of right coronary artery. ARYA Atheroscler. 2013;9(2):164-166.

6. Nadim Shah, Victoria E Cheng, et al. Percutaneous Coronary Intervention of an Anomalous Left Main Coronary Artery Arising from the Right Sinus of Valsalva Heart, Lung and Circulation. 2015;24(8):e123-e126. 
7. Angelini P, Villason S, Chan A. Normal and anomalous coronary arteries in humans. In: Angelini P, editor. Coronary artery anomalies: a comprehensive approach. Lipincott Williams and Wilkins, Philadelphia, USA, 1999. pp. 27-150.

8. Hauser M. Congenital anomalies of the coronary arteries. Heart. 2005;91(9):1240-1245.

9. Angelini P. Anomalous origin of the left coronary artery from the opposite sinus of valsalva:typical and atypical features. Tex Heart Inst J. 2009;36(4):313-315.

10. Harikrishnan S, Sonney PJ, Jaganmohan T, et al. Congenital coronary anomalies of origin and distribution in adults:a coronary arteriography study. Indian Heart J. 2002;54(3):271-275.

11. Wilkins CE, Betancourt B, Mathur VS, et al. Coronary artery anomalies. Texas Heart J. 1988;15:166-173.

12. Cheitlin MD, de Carstro CM, McAllister HA. Sudden death as complication of anomalous left coronary origin from the anterior sinus of valsalva :a not-so-minor congenital anomaly. Circulation. 1974;50(4):780-787.

13. Choi YM. Congenital anomalies of the coronary arteries detected in adulthood. Korean Circ J. 1997;27:287-295.
14. Mustafa I, Gula G, Radley-Smith R, et al. Anomalous origin of the left coronary artery from the anterior aortic sinus:a potential cause of sudden death. J Thorac Cardiovasc Surg. 1981;82(2):297-300.

15. Benge W, Martins JB, Funk DC. Morbidity associated with anomalous origin of the right coronary artery from the left sinus of valsalva. $\mathrm{Am}$ Heart J. 1980;99(1):96-100.

16. Angelini P, Velasco JA, Flamm S. Coronary anomalies:incidence, pathophysiology, and clinical relevance. Circulation. 2002;105(20):24492454.

17. Angelini P. Coronary artery anomalies:current clinical issues. Texas Heart Inst. 2002; 29(4):271-278.

18. Virmani R, Burke AP, Farb A. The pathology of sudden cardiac death in athletes. In: Williams RA, editor. The Athlete and Heart Disease: diagnosis, evaluation and management. Lipincott Williams \& Wilkins, Philadelphia, USA, 1999. pp.249-272.

19. Graidis C, Dimokritos D, Ntatsios A, et al. Percutaneous Coronary Intervention and Stenting in a Single Coronary Artery Originating from the Right Sinus of Valsalva. Hellenic J Cardiol. 2013;54(5):401-407. 